\title{
Discussion on the Future Development Direction of Electronic Data Interchange Logistics Systems in China
}

\author{
Lang Xiong, Yue Wu \\ Beijing Wuzi University, Beijing, China \\ Email: 769512001@qq.com
}

How to cite this paper: Xiong, $\mathrm{L}$. and $\mathrm{Wu}$ Y. (2017) Discussion on the Future Development Direction of Electronic Data Interchange Logistics Systems in China. American Journal of Industrial and Business Management, 7, 40-47.

http://dx.doi.org/10.4236/ajibm.2017.71004

Received: December 21, 2016

Accepted: January 16, 2017

Published: January 19, 2017

Copyright $\odot 2017$ by authors and Scientific Research Publishing Inc. This work is licensed under the Creative Commons Attribution International License (CC BY 4.0).

http://creativecommons.org/licenses/by/4.0/

c) (7) Open Access

\begin{abstract}
In the face of first-mover advantage in the logistics system of Electronic Data Interchange (EDI) from Europe and the United States and other countries, and various problems in the promotion of logistics EDI system in our country, at this stage, China should adjust and improve effectively from five directions, such as formulating standards, legal protection, enhancing cognitive, support from the government and attention from enterprises in order to truly promote the construction and development of EDI logistics system in China.
\end{abstract}

\section{Keywords}

Electronic Data Interchange, Logistics System, Development Direction

\section{Introduction}

EDI (Electronic Data Interchange) technology has been introduced into China for more than 20 years since 1990 [1]. It should be said that our country has obtained certain achievements in the exploration and development of the EDI. But compared with developed countries, the development of the EDI in our country is relatively slow. So far, the application of EDI is limited in certain regions and individual departments, and most of them are still in test and exploration. Up to $95 \%$ of top 500 enterprises in the world adopt EDI technology to process trade, deal with business documents with their business partners and rebuild the business mode and management mode according to the EDI [2].

EDI has become the dominant way for international trade in the developed countries and it will become a passport into the international market like the containers, bar code before [3]. It can be predicted that it will become a network, an information society and a paperless society supported by EDI, and EDI will get used more and more widely. Therefore, it is a key for foreign economic 
development in our country to speed up the development of the EDI.

Based on the current situation of EDI in China, this paper will sort out the problems in the EDI logistics system in our country and put forward the countermeasures to accelerate the pace of building EDI logistics system in China including formulating standards, legal protection, enhancing cognitive, support from the government and attention from enterprises for effective adjustment and improvement, which are expected to provide references for truly promoting China's EDI logistics system construction and development of reference.

\section{Problems in EDI Logistics System Development in China at Present}

\subsection{Late Beginning of EDI Technology in China, Slow Speed of Application and Promotion, and Unobvious Results}

EDI technology that is originated in the 60's was introduced to China in the early 1990s, until now it just has developed more than twenty years which means that it starts lately. In foreign countries, the development of EDI technology that has been widely used has matured, but its development is still in the "introduction" stage in China, which is still a lot of infrastructure construction and improvement, standards-setting work and slow speed of application and promotion and not obvious results so that EDI system can not developed in big step. Although after several years of development, some achievements have been made, but there is far apart from the realization of the objectives and compared with the international level.

\subsection{The Narrow Scope of Development and EDI Advantages and Benefits that Have Not Been Brought into Full Play}

In recent years, in addition to a few areas such as foreign trade, customs where EDI technology is used comparatively successfully, other areas are still trying stage. The implementation of EDI in global is based on the common EDI use for all EDI participants, which is the only way to bring into play the advantages of EDI. If EDI technology is applied in few areas, one-stop service can not be achieved. In addition, the use of EDI in China's enterprises is also due to the backwardness of the supporting sector EDI, not from the economic benefits, people on the EDI had doubts. Companies lose the confidence of the application of EDI, EDI application form a vicious cycle of the state. Figure 1 is an example of a logistics EDI system, which shows the specific issues when the owner of the shipments, logistics and transport owners and receiver owners use EDI in logistics management [4].

\subsection{Slow and Lack of EDI Standards}

Although our country has made great efforts in the study of EDI standards and has developed a number of standard documents and messages, these are relatively backward compared with the world including some Asian countries [5]. EDI standards are important parts of EDI and are the key to achieve electronic 


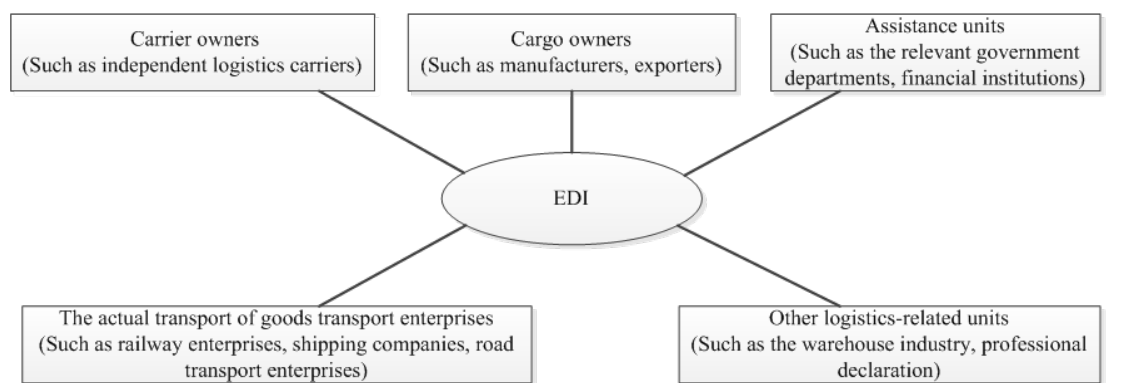

Figure 1. The EDI Logistics System.

data interchange whose quality is directly related to the development of EDI process. In addition, the personnel work for EDI standards in China is very scarce and the standard is also very slow to launch, which brought the delay in EDI technology that should be paid high attention.

\subsection{Incomplete Role That Government Plays in the Application of the Promotion Process of EDI}

EDI is a system across a variety of industries, so all industries must at the same time to achieve EDI technology and the benefits that EDI brings can be fully reflected. In order to promote the universal application of EDI, the role of government should not be underestimated. Our government in the research and promotion process of EDI technology, do not play its role in government functions, support enough intensity and enterprise supervision, and have strong desire to adopt new technology, will delay the development of EDI technology process and may have a very negative impact on China's foreign trade status [6].

\subsection{The Lack of EDI Knowledge and EDI Basic Education, Resulting in Scarce EDI Talents}

Most of the enterprises in our country are lack of basic knowledge and enough awareness of the emerging technology knowledge, and don't realize that EDI technology is the basic means for enterprises to participate in international trade in future. The emergence of this situation undoubtedly has the most direct relationship with lack of publicity and education in our country [7] [8]. At present, there are only a handful of colleges and universities that offer EDI knowledge teaching in China and there are few students who can directly receive EDI professional knowledge. So our country very lacks EDI practical talents, which will deeply affect the application of EDI in our country.

\section{The Countermeasures of Accelerating the Development of Chinese EDI Logistics System}

\subsection{Formulating Unified Domestic Standards}

Facing the EDI integration trend in the development of the logistics system that our EDI system plan to catch up with, there must be a unified corresponding standard all over the world, in order to realize effective connects and information 
integration processing among government, enterprises and social [9]. In the process, we should adhere to the combination of the introduction and the original. China should also be devoted to playing a part in formulating international standards of EDI while be in line with international standards actively.

It is a development trend of the global EDI standards at present that the world pattern that the USA and Europe both share the world has been broken. The EDIFACT in Europe has been recognized as the mainstream standard in the future development, even if the United States also offered to participate in constructing EDI-FACT standard, which marks the establishment of the international dominance of the EDIFACT on EDI system. In this context, if we start a new system sedulous, it is not worth cost as well as time and power consuming, and it will be difficult to achieve effective integration with the international. Therefore, in the overall standards, it is the domestic construction direction of EDI logistics system that breaking the domestic chaotic system category and adhering to the introduction and EDIFACT standards.

In the introduction and dominated by EDIFACT standard at the same time, China domestic also should strengthen absorption and upgrading localization for the EDIFACT standard, in keeping with foreign effective link network and the enterprises at the same time, to reach connects of local EDI technology and international technology effectively, and Chinese participation of international standards in EDI. In the process of the reform, the traditional, scattered and low-level repeated construction in their own way should be broken. The central lead national subject research to design strictly and promote unified national standard. In the process, we need to realize that the technical accumulation of EDI system construction in our country is insufficient and actively learn and absorb the international standards to catch up other countries in software. Only insist on the combination of effective introduction and positive localization, to achieve the balance of compatibility, applicability, and generalization of our country's logistics system, to lay the solid foundation for EDI technology in the field of logistics development in our country, and EDI standard construction in China.

\subsection{Effective Security Laws and Regulations}

It is necessary for rich and perfect legal protection to realize effective promotion and practice of EDI logistics technology in our country.

Our country at present is still in a very backward state of a legal protection on the use of EDI system while it has legal effect in the electronic certification service measures for the administration of administrative rules and regulations, and the contract law in commercial law for EDI, but specific system standards are not popularized and developed, which makes EDI technology popularization in could not be in accordance with the original state, so as to need be effectively guided in legislation.

To achieve effective promotion of EDI logistics system, firstly existing related civil and commercial law and unilateral law need to be made further adjustment, 
to implement the embodiment of the application of EDI technology. The existing laws itself define vaguely legal effect for EDI documents, lack of corresponding protection measures and promotional requirements, which makes the implementation of legal sense present the state of a lag. Furthermore, as changes are in the escalating of the existing network system, the original related rules are also greatly behind the rapid development of EDI technology, which brings the technical security risks that can not be overlooked. Therefore, it is essential to strengthen the effective integration of existing laws, and efficiently sort laws and regulations of logistics, trade and shipping, and even in the future, set up specialized management approach or unilateral law on EDI electronic commerce, in order that EDI logistics systems are effectively managed and actively protected.

In order to effectively promoted EDI logistics system, it is also needed to adjust the existing domestic law that integrates with the international EDIFACT standards. It is known to all that a set of technical standard is set up and compatible, behind which need complex and diverse legal to support. Therefore, integrating of technology is speeding up actively at the same time, legal standards must also be effectively adjusted, so that effective integration system can be established truly. In the process of the legal community, we should start from the current situation of the development of the logistics industry of our country, both reflecting the existing market demand and practice, and to do well in the future development of forward-looking and leading. Based on the existing domestic law and international EDIFACT standard and effective construction, obstacles in the promotion of EDI logistics system can be cleared from the system level.

\subsection{Propaganda and Education for Application to EDI Logistics}

Nowadays, The application to EDI technology in our country's logistics development is slow because a lot of obstacles come from behind and paranoid idea problem, and the problem throughout the government, enterprises and social public [10] [11]. Therefore, to achieve the effective development of the EDI logistics system, we must reverse the present situation of unclear and low level understanding for EDI technology through publicity and education, so that really the whole society, especially the relevant subjects realize great economic value and social benefits of it.

Firstly, is the importance of application of EDI technology need to be educated and propagated at government level, let the government especially the main leaders recognize that it is significant that logistics industry in our country develop the EDI. To make the government clear that EDI is not a simple information tool, its value lies in the modernization of existing management style to reshape and subversive significance to the development of logistics supply chain. As a management tool, its value is beyond a single industry, which also has huge function for transformation and service provided to our country government.

Secondly, education and propaganda about making full use of the EDI system in enterprise level should be actively made, to make enterprises, especially logis- 
tics enterprises realize that EDI has important value for its upgrading and industry development. That all kinds of enterprises in our country for EDI itself are not active is largely from understand and misunderstanding for its technology and mechanism. So enterprises understand EDI technology is the better way to promote efficiency through the way of propaganda and education rather than simple human pressure, which is helpful for the logistics enterprises to enhance their competitiveness, promote effective upgrade itself, and grasp the commanding heights of industry development.

Thirdly, a batch of EDI technology and business backbones who have professional knowledge need to be trained effectively in order to change the status that existing government and enterprises are in low level for cognitive of EDI. Training of EDI logistics system and the daily training of civil servants and enterprise's orientation can be combined to consciously cultivate professional teams, which is the basis of the construction of EDI system and promotion. Reasonable talent team construction can lay a solid human basis for the establishment of torsion and correct understanding to EDI concepts.

\subsection{Support and Promotion of the Government}

The support from government is indispensable to realize the rapid development of the logistics system in our country. We must start from the traditional problem of insufficient support from government, and effectively distinguish responsibility and positioning between the central government and local government in the EDI system promotion, to work together to achieve the wide popularity of EDI system [12].

For the central government, it is the key to make industry development planning and unified standard to break EDI development for the local government under the compartmentalization and develop EDI with system and clear national layout in hardware and software infrastructure. From the perspective of the development and layout, the central must consider and allocation the overall interests and set up orientation and construction for national and regional EDI information center and hub to eliminate redundant construction and uneven standard system. In the process of layout and design, government needs to fully understand the market demand, and meet the needs of the enterprise, increase the interactivity of EDI system network construction to realize the effective network and grid arrangement for country's communication. So that we can plan and layout for EDI development on the whole stage and eliminate the coordination that the regional development gap bring with the pace of development to promote modernization to the popularization of the EDI system in China.

The local governments should break the independent achievements of research and development and bring the main resource and energy into hardware construction. We should break the bad intervention of the local government for EDI development and make corresponding guidance to the computer and network construction to pave the way for EDI logistics system development in the region, for the enterprises, especially small and medium-sized enterprises network access 
to EDI system providing effective hardware support, which helps enterprises to reduce costs effectively. Local government should play an active role in guiding the construction of backbone networks. Only local government do well in its own infrastructure, cooperate well in the middle of the reasonable layout, low level repeated construction can be truly eliminated and the protection and isolation from the regions effectively are broken, to really realize effective Internet EDI across regions of logistics system and achieve the effective interaction of data and information, making that the real advantage of EDI technology is able to develop.

\subsection{The Attention and Application of from Enterprises}

In order to realize the wide application of EDI technology in logistics industry, the guidance from government must be indispensable [13]. But if systemic application and popularization are formed really, the enterprise need to be really involved and strengthen the focus on EDI technology system and the depth of application to realize the effective transformation and upgrade of industry.

Logistics enterprises and enterprises that need logistics largely should pay attention to processing function for information and data of EDI technology, not only create own EDI system, but also achieve effective integration with its own management information system to realize the intrinsic consistency between the information system of enterprise itself. At the same time, enterprises should actively reach information interaction with effective networking from industry, customers, suppliers and other stakeholders and give full play to the technological advantage of the EDI. After all, the efficiency advantage of EDI come from effective interaction of the data and the more comprehensive the network of the interaction are and the more abundant processed information are, the greater economies of scale it brings. Therefore, it is a focus that great attention is paid to EDI and the interaction construction is attached in the current.

When enterprises apply to EDI logistics system, they should consider its own size and the processing power of EDI technology. Besides, enterprises should formulate different development strategy according to their own situation. The large enterprises with rich technical force and capital should analyze the feasibility and make project implementation plan, based on demand analysis. Enterprises can also analyze, reorganize and develop secondly combing EDI software to make that the EDI system combine with its own logistics processing requirements. The enterprises whose technical force is weak and that lack of capital can temporarily choose EDI center access to develop their own EDI system after they enhance capital and technology level.

\section{Conclusion}

At present, the application of EDI technology in the field of logistics has become the global focus of development, in the face of growing demand for logistics in our country, the modern reform with EDI logistics system for breach should be the development direction in the future. That will need to identify the main 
existing problems, with the joint efforts of the whole society, and realize the EDI technology matures with each other and the electronic informatization of logistics enterprises in transition to really promote the span development of China's logistics industry and logistics related.

\section{References}

[1] Chen, S.M. (2015) Introduction to Introduce the Reason and the Application of the Electronic Data Interchange EDI. Guangdong Science and Technology, 88-89.

[2] Huang, Q.Z. (2011) EDI Technology and Its Applications. Profession, 24, 99.

[3] Feng, J.J. (2013) EDI Technology to the Enterprise Logistics Business Impact Analysis. Journal of Logistics Technology, 6, 61-63.

[4] Yu, D.F. (2013) Based on the Analysis of Application of EDI Technology in Modern Logistics Management. Journal of TV University Institute of Technology, 1, 31-33.

[5] Zhang, H.Y. (2010) International Logistics. Northeast University of Finance and Economics Press, Dalian, 98-102.

[6] Dong, L. (2010) Logistics Operation Management. Peking University Press, Beijing, 21-25.

[7] Zhang, H.Y. (2012) China EDI Contract Legal Problems of the Promoted Application and Legislative Suggestions. Journal of Dalian Maritime University (Social Science Edition), 1, 7-10.

[8] Yang, R. (2014) Logistics Information Platform Which Is Based on EDI Technology. Journal of Logistics Technology, 9, 56-57.

[9] Guo, W. (2013) Talk about the Application of Logistics Information Technology. Journal of Electronic Test, 21, 121-122.

[10] Cai, Y.Y. (2013) Support VMI Model of EDI System Technology Research and Application. Shanghai Jiaotong University, Shanghai.

[11] Chen, X. (2013) EDI and B2B Applications. Small- and Medium-Sized Enterprise Management and Science and Technology, 9, 305-306.

[12] Wang, R.Q. (2015) The Application of EDI in Military Logistics. Journal of Logistics Technology, 11, 161-163.

[13] Xu, D.D. (2012) Logistics Enterprise Application of EDI Technology Strategy Research. Modern Economic Information, 60-61. 